\title{
Peculiarities of Intersystemic Correlation Relationships of M-Response and F-Wave Characteristics in the Forearms Symmetric Muscles Which Participate in the Implementation of Multiple Coordinated Bimanual Movements
}

\section{Peculiaridades de las relaciones de correlación intersistémica de las características de la respuesta $M$ y la onda $F$ en los antebrazos Músculos simétricos que participan en la implementación de múltiples movimientos bimanuales coordinados}

\author{
Lada O. Mashoshina \\ student Kursk State Medical University \\ ORCID: https://orcid.org/0000-0002-4402-5723 \\ Pavel V. Tkachenko \\ doctor of Medical Sciences, associate Professor of the department of normal physiology Kursk \\ State Medical University \\ ORCID: https://orcid.org/0000-0002-2725-6482 \\ Nadezhda I. Belousova \\ assistant of the department of normal physiology Kursk State Medical University \\ ORCID: https://orcid.org/0000-0003-0296-5335 \\ Victor T. Dudka \\ candidate of medical sciences, associate professor of the department Pathological Anatomy Kursk \\ State Medical University \\ ORCID: https://orcid.org/0000-0001-5027-6011 \\ Svetlana A. Dolgareva \\ doctor of Medical Sciences, associate Professor of the department of Biological Chemistry Kursk \\ State Medical University \\ ORCID: https://orcid.org/0000-0002-9984-5972
}

Received 09-08-20 Revised 10-10-20

* Correspondence

Email: lada-mashoshina@yandex.ru
Accepted 12-12-20 On line 03-12-21
Lada O. Mashoshina, Pavel V. Tkachenko, Nadezhda I. Belousova, Victor T. Dudka, Svetlana A. Dolgareva. (2021). Peculiarities of Intersystemic Correlation Relationships of M-Response and F-Wave Characteristics in the Forearms Symmetric Muscles Which Participate in the Implementation of Multiple Coordinated Bimanual Movements. Propósitos y Representaciones, 9 (SPE3), e1129. Doi: http://dx.doi.org/10.20511/pyr2021.v9nSPE3.1129 


\begin{abstract}
The organization of combined voluntary goal directed movements of hands has remained a serious scientific problem with a pronounced applicable nature. Insufficiency of a procedural framework and clear quantitative and qualitative criteria causes gaps and difficulties in professional selection, the effectiveness diagnosis of work-out session in sports and rehabilitation within remedial treatment. The aim of the investigation is to study the adjustment and co-adjustment of the effector apparatus elements, which are the basis of bimanual coordination, in the groups of male and female trial subjects. In the following study, based on informed consent in accordance with the ethics committee requirements, 75 subjects ( 39 men and 36 women) at the age of 18-20 took part. F-wave and M-response parameters registration was carried out by means of NMA-4-01 "NEUROMIAN" neuromyoanalyzer (Taganrog, Russia) according to the standard method. It has been established that the nerve centers responsible for the work of homonymous muscles in the right and left forearms, innervating synergists and antagonists, are to a certain extent in the initial adjustment and co-adjustment according to the level of activity, which determines not only the moment of the excitement onset, but also the speed of its irradiation. The revealed manifestations of adjustment and co-adjustment have pronounced sex differences. Proceeding from the fact that female trial subjects have a lower level of bimanual movements if compared with men, it can be assumed that the revealed features of correlational relationships determine, to a certain extent, coordination abilities of men and women.
\end{abstract}

Keywords: stimulation myography, F-wave, M-response, correlation analysis.

\title{
Resumen
}

La organización de movimientos de manos combinados, voluntarios y dirigidos a objetivos, sigue siendo un problema científico grave con una pronunciada naturaleza aplicable. La insuficiencia de un marco procedimental y de unos criterios cuantitativos y cualitativos claros provoca lagunas y dificultades en la selección profesional, el diagnóstico de eficacia de la sesión de entrenamiento en el deporte y la rehabilitación dentro del tratamiento reparador. El objetivo de la investigación es estudiar el ajuste y coajuste de los elementos del aparato efector, que son la base de la coordinación bimanual, en los grupos de sujetos de prueba masculinos y femeninos. En el siguiente estudio, basado en el consentimiento informado de acuerdo con los requisitos del comité de ética, participaron 75 sujetos (39 hombres y 36 mujeres) con edades entre 18 y 20 años. El registro de los parámetros de la onda $\mathrm{F}$ y la respuesta $\mathrm{M}$ se realizó mediante el neuromioanalizador NMA-4-01 "NEUROMIAN" (Taganrog, Rusia) según el método estándar. Se ha establecido que los centros nerviosos responsables del trabajo de los músculos homónimos de los antebrazos derecho e izquierdo, sinérgicos y antagonistas inervadores, se encuentran en cierta medida en el ajuste y coajuste inicial según el nivel de actividad, lo que determina no sólo el momento del inicio de la excitación, pero también la velocidad de su irradiación. Las manifestaciones reveladas de ajuste y co-ajuste han marcado diferencias sexuales. Partiendo del hecho de que las mujeres de prueba tienen un menor nivel de movimientos bimanuales en comparación con los hombres, se puede suponer que las características reveladas de las relaciones correlacionales determinan, en cierta medida, las capacidades de coordinación de hombres y mujeres.

Palabras clave: miografía de estimulación, onda F, respuesta M, análisis de correlación.

\section{Introduction}

The issues covering the peculiarities of bimanual coordination are currently of immediate interest due to the need for a comprehensive assessment of this body function during professional selection, occupational guidance, assessment of work-out process dynamics in sports and recovery during rehabilitation measures. On earlier occasions, the levels of voluntary goal directed hand movements in trial subjects of both sexes were investigated, correlates of voluntary motor activity and cerebral circulation were described, some aspects of effector support of voluntary bimanual movements were studied from the standpoint of a systematic approach (Tkachenko, 2004). Equally important are the features of linear and curvilinear correlation of myography stimulation 
characteristics described in our previous studies, which reflect the functional state of not only the interested peripheral neuromuscular system, but also the structures of the central nervous system responsible for planning, adjustment and implementation of voluntary motor programs (Nikolaev \& Samojlov, 2003; Rusanova \& Lakhman, 2008; Tkachenko, 2019). There is no doubt that the study of electrical activity of nerves and muscles parameters provides valuable information about the organization and functioning of the motor analyzer as a whole.

\section{Purpose of the study}

Despite all the above mentioned, the mechanisms of the central and peripheral nervous systems functioning remain insufficiently studied from the standpoint of adjustment and co-adjustment of the effector apparatus elements in the groups of male and female trial subjects, which has become the aim of our study.

\section{Materials and methods of investigation}

In the following study, based on informed consent in accordance with the ethics committee requirements, 75 subjects (39 men and 36 women) at the age of 18-20 took part. F-wave and Mresponse parameters registration was carried out by means of NMA-4-01 "NEUROMIAN" neuromyoanalyzer (Taganrog, Russia). The nerves being stimulated were: $\mathrm{n}$. Medianus (median nerve), the stimulation site is the cubital fossa at the tendon medial edge $\mathrm{m}$. Biceps, the place of potentials abduction M. abductor pollicis brevis; $n$. Ulnaris (ulnar nerve), the site of stimulation at the level of radiocarpal joint directly medial to the postulnar bone, the place of potential abduction $\mathrm{m}$. thenar and hypothenar, $\mathrm{m}$. Interosseus; $\mathrm{n}$. Radialis (radial nerve), the site of stimulation is a point on the border of the upper and middle third of the forearm along the ulna, the place of the potential abduction m. Extensor pollicis longus (Zenkov \& Ronkin, 2004; Nikolaev, 2003; Sinelnikov et al., 2018). The parameters of the F-wave and M-response on the right and left forearm were studied. Surface electrodes were used as pickup electrodes. The active electrode was located on the myogaster, and the reference electrode was distal to the active one. The Electrostimulator electrodes (observing the polarity) were placed on the selected active point of the nerve under investigation. A ground electrode was placed between the stimulating and pickup electrodes. Anatomical-clinical and anatomical-topographic guidelines were used to find the locations of the stimulating and pickup electrodes (Nikolaev, 2003; Gekht et al. 1997). A footoperated switch and the electrostimulator regulator were used for stimulation. Bipolar stimulation with rectangular current impulses was applied. The number of stimuli is 20 with $1 \mathrm{~Hz}$ frequency. Stimulation duration is $0.1 \mathrm{~ms}$ with zero delay and supramaximal intensity. Dynamic range of registration M: $80000 \mu \mathrm{V}, \mathrm{F}-8000 \mu \mathrm{V}$. Bandwidth is from $10 \mathrm{~Hz}$ to $2000 \mathrm{~Hz}$ with the resection filter off. The stimulus intensity threshold is $50 \mathrm{~mA}$. The sweep rate is $2.5 \mathrm{~ms} / \mathrm{d}$. the snsitivity $\mathrm{M}$ : $2 \mathrm{mV} / \mathrm{d}$ - F: $200 \mathrm{mV} / \mathrm{d}$. The following parameters were considered as diagnostic ones: Mresponse latency $(\mathrm{ms})$, M-response amplitude $(\mathrm{mV})$, minimum (min), average (med) and maximum $(\max )$ values of F-wave, ratio of F-wave/M-response amplitudes (min, med, max) in \%, the difference in latencies F-wave - M-response (min, med, max) in ms, as well as the minimum, average and maximum velocity of conduction along the nerve. Only the parameters of the first Mresponse were used for calculations, which is associated with its stability when using supramaximal stimuli.

When processing statistically, the mean values of the considered characteristics with errors were calculated. To assess the relationship, a complete correlation analysis was performed where the calculation of correlation coefficients (r) and correlation relations $(\eta)$ of the registered indicators was carried out. In order to determine the level of multiple relations, $\Sigma r+\eta$ was calculated for each indicator without taking into account the sign. 


\section{Results and discussion}

When analyzing the total multifaceted correlation of myography characteristics obtained by stimulation of the right forearm radial nerve with similar indicators of the contralateral forearm in the group of male trial subjects (table), it was found out that the highest level of correlations belongs to the mean values of the latencies difference, nerve conduction velocity and the amplitudes ratio of characteristics under consideration. Among the characteristics of the homonymous nerve on the left, the maximum value of the F-wave latency and, as with right-sided stimulation, the average values of the amplitudes ratio and nerve conduction velocity show the greatest strength of relationship. The relationship level of the described indicators is significantly statistically higher than that of the following them values.

When stimulating the median nerve on the right, the first three ranks in men in terms of the correlation level with the characteristics of the homonymous left nerve occupy the maximum value of the amplitude ratios, and the average values of the latencies difference and the nerve conduction velocity as well. The maximum values of the F-wave latency and the latencies difference, and the minimum value of the nerve conduction velocity as well are mostly correlated from the contralateral point. A characteristic feature, as in the previous case, is the differences reliability with the following values of the total correlation of the myography characteristics.

Table 1. Intersystem correlation of M-response and F-wave characteristics on the right/left

\begin{tabular}{|c|c|c|c|c|c|c|c|c|c|c|c|c|c|}
\hline \multirow{2}{*}{$\begin{array}{l}\text { M- } \\
\text { respo } \\
\text { nse } \\
\text { laten } \\
\text { cy }\end{array}$} & \multirow{2}{*}{$\begin{array}{l}\text { M- } \\
\text { respo } \\
\text { nse } \\
\text { ampli } \\
\text { tude }\end{array}$} & \multicolumn{3}{|c|}{ F-wave latency } & \multicolumn{3}{|c|}{$\begin{array}{c}\text { F-wave } \\
\text { amplitude/M- } \\
\text { response } \\
\text { amplitude }\end{array}$} & \multicolumn{3}{|c|}{$\begin{array}{c}\text { F-wave latency - } \\
\text { M-response } \\
\text { latency }\end{array}$} & \multicolumn{3}{|c|}{$\begin{array}{c}\text { Conduction } \\
\text { velocity }\end{array}$} \\
\hline & & $\min$ & $\underset{\mathrm{d}}{\mathrm{me}}$ & $\max$ & $\min$ & med & $\max$ & $\min$ & med & $\max$ & $\min$ & med & $\max$ \\
\hline \multicolumn{14}{|c|}{ Males } \\
\hline \multicolumn{14}{|c|}{ Radial nerve } \\
\hline 3,39 & $2,321 /$ & 1,11 & 3,2 & 1,34 & 1,55 & 5,37 & 4,31 & 0,6 & 6,65 & $0 /$ & 3,74 & 6,45 & 1,22 \\
\hline $2 /$ & 1,759 & $2 /$ & $18 /$ & $6 /$ & $1 /$ & $4 * /$ & $8 /$ & $71 /$ & $3 * /$ & 2,74 & $2 /$ & $0 * /$ & $2 /$ \\
\hline 3,13 & & 1,96 & 3,7 & 4,13 & 3,66 & 4,11 & 2,84 & 1,7 & 3,73 & 8 & 2,80 & 4,90 & 1,30 \\
\hline 4 & & 7 & 09 & $6^{*}$ & 4 & $1 *$ & 7 & 54 & 0 & & 2 & $5 *$ & 6 \\
\hline \multicolumn{14}{|c|}{ Median nerve } \\
\hline 2,14 & $3,300 /$ & 1,36 & 5,2 & 0,57 & 6,45 & 3,65 & 7,79 & 0,8 & 6,72 & 1,71 & 4,06 & 7,43 & 1,71 \\
\hline $8 /$ & 3,575 & $8 /$ & $95 /$ & $6 /$ & $1 /$ & $1 /$ & $1 * /$ & $74 /$ & $6 * 1$ & $5 /$ & $5 /$ & $6 * /$ & $1 /$ \\
\hline 4,65 & & 4,59 & 4,3 & 6,17 & 2,24 & 2,82 & 3,41 & 2,2 & 3,48 & 4,62 & 6,00 & 4,18 & 0,80 \\
\hline $5 *$ & & 9 & 12 & $5 *$ & 0 & 0 & 3 & 28 & 3 & $7 *$ & $0 *$ & 4 & 1 \\
\hline \multicolumn{14}{|c|}{ Ulnar nerve } \\
\hline 1,69 & 3,787 & 2,22 & 1,0 & 2,54 & 1,42 & 1,40 & 2,05 & 2,1 & 1,97 & 2,87 & 2,18 & 2,43 & 2,28 \\
\hline $5 /$ & $* /$ & $0 /$ & 91/ & $1 * /$ & $6 /$ & $1 /$ & $1 /$ & 29/ & $2 /$ & $2 * 1$ & $9 /$ & $6 /$ & $5 /$ \\
\hline 1,05 & 2,603 & 0,54 & 1,2 & 0,89 & 6,07 & 6,91 & 6,73 & 1,3 & 0 & 0 & 2,70 & 0 & 0 \\
\hline 1 & & 8 & 10 & 0 & $0^{*}$ & $0 *$ & $3 *$ & 79 & & & 1 & & \\
\hline \multicolumn{14}{|c|}{ Females } \\
\hline \multicolumn{14}{|c|}{ Radial nerve } \\
\hline 3,13 & 5,130 & $0 /$ & 4,3 & 1,37 & 1,52 & 4,43 & 1,88 & 0,3 & 5,61 & 0,58 & 1,00 & 5,75 & 1,00 \\
\hline $4 /$ & $* /$ & 2,16 & $13 /$ & $9 /$ & $5 /$ & $5 /$ & $0 /$ & $33 /$ & $0 * 1$ & $4 /$ & $5 /$ & $9 * 1$ & $4 /$ \\
\hline 3,28 & 3,117 & 4 & 3,7 & 2,17 & 0,33 & 3,86 & 0,67 & 2,8 & 4,60 & 1,83 & 1,23 & 4,92 & 0,67 \\
\hline 7 & & & 66 & 8 & 1 & $5 *$ & 1 & 48 & $6^{*}$ & 1 & 9 & $6^{*}$ & 8 \\
\hline \multicolumn{14}{|c|}{ Median nerve } \\
\hline 2,61 & 4,959 & 0,35 & 2,3 & 0,53 & 1,60 & 1,05 & 1,50 & 0,3 & 3,53 & 1,22 & 3,99 & 1,11 & 0,33 \\
\hline $0 /$ & $* /$ & $2 /$ & $90 /$ & $8 /$ & $3 /$ & $7 /$ & $3 /$ & $32 /$ & $5 * 1$ & $7 /$ & $4 * 1$ & $2 /$ & $1 /$ \\
\hline 2,59 & 2,936 & 3,04 & 2,4 & 0,65 & 0,66 & 0,66 & 0 & 2,1 & 2,42 & 3,46 & 1,15 & 1,85 & 1,54 \\
\hline 7 & $*$ & $0^{*}$ & 10 & 1 & 3 & 3 & & 30 & 9 & $9^{*}$ & 3 & 3 & 9 \\
\hline \multicolumn{14}{|c|}{ Ulnar nerve } \\
\hline 0,53 & $3,347 /$ & 1,83 & 3,5 & 2,98 & 3,48 & 8,44 & 7,56 & 3,5 & 3,61 & 1,81 & 3,26 & 3,33 & 5,24 \\
\hline
\end{tabular}




\begin{tabular}{|c|c|c|c|c|c|c|c|c|c|c|c|c|c|}
\hline $3 /$ & 1,628 & $8 /$ & $26 /$ & $2 /$ & $6 /$ & $3 * /$ & $1 * /$ & $82 /$ & $9 /$ & $1 /$ & $0 /$ & $0 /$ & $4 * /$ \\
0,53 & & 2,32 & 3,6 & 6,69 & 1,33 & 4,11 & 4,92 & 4,3 & 2,94 & 6,41 & 4,90 & 4,46 & 4,30 \\
3 & & 4 & 48 & $5 *$ & 4 & 3 & $8 *$ & 18 & 4 & $9 *$ & 4 & 5 & 9 \\
\hline
\end{tabular}

Note: with $* \Sigma r+\eta$ are marked, which occupy the first three ranks in terms of the level of total multiple correlation.

Among the right ulnar nerve characteristics under consideration, the amplitude of the Mresponse and the maximum values of the F-wave latency and the latencies difference show the highest level of total correlation with the characteristics of the contralateral side. The levels of correlation relationships in the considered ranked series have unreliable differences. As for the ulnar nerve on the left, the first three ranks here in terms of the correlation relationships level belong to the minimum, average and maximum values of the F-wave and the M-response amplitudes ratio. Here, the first described ranks have a significantly more pronounced multiple correlation.

The revealed peculiarities of the total multiple correlation of the stimulation myography characteristics in male trial subjects probably indicate that the activation co-adjustment of the nerve centers innervating the corresponding muscle structures results in the ratio optimization of both $\mathrm{F}$ and $\mathrm{M}$ responses initiation, as evidenced by the relationship of latencies, and which manifests itself in the organization of nerve conduction velocity as well. The importance of the neuromuscular group and its participation in the implementation of voluntary movements is in no doubt. The median nerves $\sum r+\eta=53.112$ are notable for their highest total correlation, the second rank is occupied by the radial nerves - 43.691, and the third place is occupied by the ulnar nerves with the sum of the correlation coefficients and correlation relations - 30.095.

In the group of female trial subjects, among the indicators of the F-wave and M-response obtained during the right radial nerve stimulation with similar characteristics of the contralateral forearm, the highest level of correlations belongs to the M-response amplitude, and the average values in the latencies difference and the nerve conduction velocity as well. Therewith, the values of the first three ranks are significantly higher than those of the succeeding ones. Contralaterally, the first three ranks are occupied with the mean ratio values of the F-wave and the M-response amplitudes, the difference in the corresponding latencies and the nerve conduction velocity. Moreover, the values of the first two ranks are statistically significantly higher than those of the following ones.

When stimulating the median nerve on the right, the ranking of the obtained indicators according to the level of total multilateral correlation relationships showed that the M-response amplitude, the average value of the latency difference and the minimum value of the nerve conduction velocity have the strongest relationships. Among the characteristics of the homonymous nerve on the left, the M-response amplitude, the minimum value of the F-wave latency and the maximum value in the latencies difference are positioned at the beginning of the ranked row. The significant level of differences in the correlation of the indicators described with the succeeding ranks both on the right and on the left is characteristic.

Among the characteristics belonging to the right ulnar nerve, the mean and maximum ratio value of the F-wave and M-response amplitudes, as well as the maximum value of the nerve potential conduction velocity, have the greatest correlation with the indicators of the contralateral side. On the left, the first three ranks are occupied with the maximum values of the F-wave latency and the amplitudes ratio and the latencies difference. The values of the first two ranks are significantly statistically higher than those of the subsequent ones.

In female trial subjects, in presence of statistically equal total correlation (126.898 - men and 114.639 - women), there is a slightly different distribution of the correlation relationships strength. Thus, the highest level of correlations is characteristic for the ulnar nerves $\left(\sum=52.589\right)$, the second rank is occupied by the radial nerves $\left(\sum=35.507\right)$, and at the last level are for the median nerves $\left(\sum=25.543\right)$, which occupy the first rank in the group of males. The activation of 
nerve structures and the nerve conduction velocity, and their lateralization as well, are obviously determined by the functional load and the peculiarities of voluntary movements biomechanics.

\section{Conclusion}

Thus, the results obtained indicate that the nerve centers responsible for the homonymous muscles work in the right and left forearms, innervating the synergists and antagonists, are to a certain extent in their initial adjustment and co-adjustment according to the level of activity, which determines not only the moment of excitation onset, but also its conduction velocity. The revealed manifestations of adjustment and co-adjustment have pronounced sex differences. Proceeding from the fact that female trial subjects have a lower level of bimanual movements if compared to males (Tkachenko, 2004), it can be assumed that the revealed features of correlational relationships determine, to a certain extent, the coordination abilities of males and females.

\section{References}

Gekht B.M. et al. (1997). Electromyography in the diagnosis of neuromuscular diseases. Taganrog, 370 p., Russian

Nikolaev, S.G. (2003). Manual on clinical electromyography. Ivanovo, 264 p., Russian

Nikolaev, S.G., \& Samojlov, M.I. (2003). Normal indicators of the F-wave when registering from the upper extremities. Functional diagnostics, 2, 56-58. Russian

Petrova, E.V. (2019). Correlation relationships between the characteristics of bimanual coordination and indicators of cerebral hemodynamics. Regional Bulletin, 18(33), 11-12, Russian

Rusanova, D.V., Lakhman, O.L. (2008). The use of the F-wave in the diagnosis of the peripheral nerves functional state in firefighters. Bul. of Sib. Medicine, 5, 113-117., Russian

Sinelnikov, R.D., Sinelnikov, Ya.R., Ya Sinelnikov, A. (2018). Atlas of human anatomy: textbook: In 4 volumes. Vol. 1. - 8th ed. revised/R.D. Sinelnikov, M.: RIA "New Wave": Publisher Umerenkov, 488 p., Russian

Tkachenko, P.V. (2004). Functional relationship of characteristics of the sensorimotor sphere and voluntary motor activity components/ thesis for the degree of $\mathrm{PhD}$ in Medicine. Kursk, 184 p., Russian

Tkachenko, P.V. (2019). Intersystem curvilinear correlations of the stimulation electroneuromyography characteristics in the forearms symmetrical nerves. Regional bulletin, 17(32),16-17 p., Russian.

Tkachenko, P.V. (2019). Intersystem linear correlation relationships of the stimulation electroneuromyography characteristics in the forearms symmetric nerves. Regional Bulletin, 17(32), 2-3 p., Russian

Zenkov, L.R., \& Ronkin, M.A. (2004). Functional diagnostics of nervous diseases: doctors' manual. - M: MEDpress-inform. 578 p., Russian 